\title{
Impact of the corona virus disease 2019 pandemic on physiotherapy services in Nigeria
}

\author{
Daha Garba Muhammad and Jamila Suleiman Musa \\ Physiotherapy Department, \\ Abubakar Tafawa Balewa University Teaching Hospital Bauchi, Bauchi, Nigeria
}

\begin{abstract}
Purpose - This study aimed to explain the impact of the corona virus disease 2019 (COVID-19) pandemic on physiotherapy services in Nigeria.

Design/methodology/approach - This is a commentary piece.

Findings - The pandemic has potential of reducing efficacy of physiotherapy services. It also showed that the mental health of local physiotherapists was badly affected. On the other hand, the pandemic allowed physiotherapists to support infectious disease prevention and control and as well as providing awareness of the role of physiotherapy in the management of respiratory diseases.
\end{abstract}

Originality/value - It shows the effect of COVID-19 on physiotherapy care.

Keywords Coronavirus, COVID-19, Rehabilitation, Pandemic, Nigeria

Paper type Commentary

\section{Introduction}

Coronavirus disease 2019 (COVID-19) is caused by the severe acute respiratory syndrome coronavirus 2 (SARS-CoV-2), a novel coronavirus from the same family as SARS-CoV and Middle East respiratory syndrome coronavirus (MERS-CoV) with outbreaks of SARS in 2003 in the Guangdong province in China and MERS-CoV in Saudi Arabia in 2012 [1]. Not long after Nigeria reported its first case of COVID-19 on 27 February 2020, the virus was declared a world pandemic by the World Health Organization (WHO). The number of confirmed cases continued to increase in number especially in the densely populated cities of Lagos and Abuja, the capital city of the country, in the early stages. This led to the enforcement of lockdown in these cities to prevent further transmission of the virus, and a level of success was achieved [2]. However, the number of confirmed cases in other states (regions) of the country continued to rise despite enforcing a nationwide lockdown [3].

Lockdown meant staying indoors with strict movement restrictions for any purpose within and outside the country except for essential services [4]. This enforcement affected healthcare delivery in all aspects, especially in low- and middle-income countries [5]. In Nigeria, being a developing country due to its lack of infrastructure, the effect led to the transformation of entire hospitals to isolation centers in some parts of the country, while only some parts of other hospitals were transformed into isolation centers [6]. In addition, private healthcare centers and even nonhealthcare centers were also transformed into isolation centers [6], to the extent that some individuals were even isolated in their respective homes

(c) Daha Garba Muhammad and Jamila Suleiman Musa. Published in Journal of Health Research. Published by Emerald Publishing Limited. This article is published under the Creative Commons Attribution (CCBY 4.0) licence. Anyone may reproduce, distribute, translate and create derivative works of this article (for both commercial and non-commercial purposes), subject to full attribution to the original publication and authors. The full terms of this licence may be seen at http://creativecommons. org/licences/by/4.0/legalcode

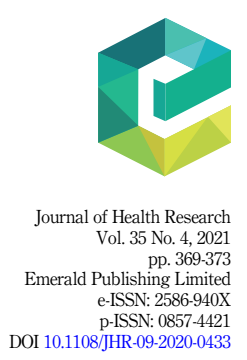


JHR

35,4

due to lack of space. The resulting lack of space inevitably necessitated affected hospitals to discharge improved patients and restrict patient admission to only emergency cases.

Physiotherapeutic services are aimed at developing, maintaining and aiding the recovery of movement and functional abilities of a patient and thus improving quality of life [7]. Therefore, both COVID-19 and non-COVID-19 cases require the services of physiotherapists during a pandemic [8]. Physiotherapists have a vital role to play in the management of COVID-19 patients [7]. Based on this, international organizations such as the World Confederation of Physical Therapists (WCPT) established guidelines to aid physiotherapists in managing COVID-19 patients. Besides caring for COVID-19 patients, physiotherapists were also expected to attend to other non-COVID-19 patients. The COVID-19 pandemic affected healthcare delivery not only in developing countries but developed countries too [5]. This paper aims to present the impact of this pandemic on physiotherapy services in Nigeria.

\section{Challenges during the pandemic}

A total of $53 \%$ of inpatient services were affected by the pandemic globally [5]. In Nigeria, to create more bed space due to some wards being transformed into COVID-19 isolation centers, improved patients were discharged from the hospital, thus shortening the duration of inpatient stays. Other countries such as Belgium, India, Tanzania and the UK had also reduced the length of hospitalization of patients [9]. This affected the delivery of physiotherapy services to patients requiring such services because it reduced the time to treat patients and train their family members in the care of the patients [9].

During the pandemic, physiotherapeutic in-patient services were provided by seniors and very experienced therapists in some centers and in other centers by juniors (interns) with no adequate supervision. In either case, this affects the level of skill acquisition of the junior and less experienced therapist, especially the interns doing their one-year training. Internship training involves rotation of the interns in at least five of the physiotherapy specialties: neurology, orthopedic, pediatrics, women's health and cardiopulmonary with community and sports physiotherapy as the case may be. Therefore, switching over from one specialty to another was expected to take place every two or three months depending on the number of specialties available at the training center. However, due to the duration of the COVID-19 pandemic, some interns were unable to learn much in certain units before proceeding to the next unit. Interns were also expected to make presentations at the end of each unit, but due to the restriction of public gatherings, the presentations were also suspended. Exceptionally, and of note, junior therapists with less experience in India [10] and Portugal [8] were also reported to be involved in the management of patients during the pandemic.

Outpatient services were equally affected, though healthcare services were considered essential and as such, the movement for such purpose was not restricted. The number of outpatients seen in a day was scaled down in order to avoid congestion and to give room for physical distancing, as such patients who required physiotherapy services two to three times a week were provided with support once in two or eight weeks. This is also the case in other countries such as Portugal [8], India, Tanzania and the UK [9]. This greatly affects the patient's prognosis, especially in physiotherapy services where the outcome of the interventions depends on the frequency of the number of the repetition of the task given. Just like pharmacological intervention, exercise therapy needs to be prescribed with appropriate dosage to achieve the maximum therapeutic effect of the exercise. For example, before neuroplasticity takes place in a neurological patient, a minimum of 300-800 repletion or practice of $\geq 3$ hours (Abdullahi in 2014 and Ashby et al.in 2010 cited in Abdullahi [11]) is required per day which may not be realistic at home owing to the poor adherence of these prescribed programs [12]. The prognosis of patients with elbow or any joint stiffness can also be affected due to the nature of treatment that should be frequent and repetitive. 
Healthcare providers are among individuals with the highest risk of contracting the virus [13], therefore the mental state of healthcare providers including therapists is also affected. This is because their services require manual contact with patients [14]. The fear [15] and anxiety of contracting and transmitting the virus to family members [13] led to the improvisation of treatment including not touching the patient unless necessary, necessitating patients to use face masks, use sanitizers and the provision of instructions to patients from a distance away [8]. Patients were asked to use hand gloves when using any equipment in the gymnasium in addition to compulsory face mask use. Due to these decisions, the patient's fear of contracting the virus, further exacerbated by widespread misinformation, misconception, and attitudes toward COVID-19 [16] in the hospital, as well as the poverty level[5] led some to quit/reduce outpatient visitations.

\section{Opportunities during the pandemic}

Despite the challenges, the pandemic had led to an increase in awareness of the role of physiotherapy in respiratory care. During the pandemic, the Nigerian Society of Physiotherapy inaugurated a COVID-19 respond task force at both national and state level, that were expected to collaborate with national and various state COVID-19 task force in the management of COVID-19 patients in the country. In addition, physiotherapists had the opportunity to advocate on the prophylaxis effect of prescribed exercise to infection by boosting immunity and the role of physiotherapy even after the pandemic [17]. Physiotherapists were also involved in the training on infection prevention and control at various hospitals. However, despite it being established that physiotherapists are less involved in the management of COVID-19 patients in Africa [18], it still sheds light on the role of physiotherapists during the COVID-19 pandemic.

It was argued that the pandemic would provide the opportunity for the emergence of a physiotherapy specialty, termed infectious physiotherapy [19]. This may be viable considering the number of infectious diseases such as poliomyelitis, tetanus and meningitis among others of which physiotherapists are involved in their management. However, unlike other countries such as India [20], the curriculum of Nigerian physiotherapy undergraduate training does not include epidemiology or microbiology as separate courses of study in the same way as other basic clinical courses such as anatomy [21]. Therefore, this pandemic could serve as a call to consider the inclusion of these two basic clinical courses during undergraduate training.

Furthermore, as a result of the outpatient visitation service being rescheduled to once or twice in eight weeks, patients were given adequate home programs to practice at home. Additionally, therapists and their patients exchanged mobile phone numbers allowing patients to keep in touch with their therapists. This has also provided an avenue for telerehabilitation in Nigeria.

\section{Conclusion}

The COVID-19 pandemic has affected physiotherapists, their patients and physiotherapy services in many ways including having an effect on the mental health of therapists as well as a reduction in the efficiency of treatment that relies on regular repetition of treatment. On the other hand, the pandemic has increased awareness of physiotherapy roles in respiratory conditions.

\section{References}

1. Zhu N, Zhang D, Wang W, Li X, Yang B, Song J, et al. A novel coronavirus from patients with Pneumonia in China, 2019. N Engl J Med. 2020 Feb; 382(8): 727-33. doi: 10.1056/NEJMoa2001017. 
JHR

35,4
2. Muhammad DG. Effectiveness of lockdown (from 30th March to 30th May, 2020) in curbing the spread of coronavirus: Lagos, Abuja and Ogun as a case study. Yen Med J. 2020; 2(4): 7-9.

3. Oglinlinks. Nigeria extends nationwide lockdown by 4 weeks. [cited 2020 September 20]. Available from: https://oglinlinks.new/opec/news.

4. CNBC Africa. COVID-19: Nigeria extends lockdown by two weeks in Lagos, Abuja and Ogun states. [updated 2020 April 13; cited 2020 September 20]. Available from: www.cnbnafrica.com/ coronavirus/2020/04/13/COVID-19-Nigeria-exrends-lockdown-by-two-weeks-in-Lagos-Abuja-andOgun-states.

5. World Health Organization [WHO]. Pulse survey on continuity of essential health services during the COVID-19 pandemic: interim report. Geneva: WHO; 27 August 2020. 2020.

6. Radio Nigeria. Kano establishes more isolation centres. [cited 2020 September 20]. Available from: https://www.radionigeria.gov.ng/2020/05/02/kano-establishes-more-isolation-centres.

7. Thomas P, Baldwin C, Bissett B, Boden I, Gosselink R, Granger CL, et al. Physiotherapy management for COVID-19 in the acute hospital setting: clinical practice recommendations. J Physiother. 2020 Apr; 66(2): 73-82. doi: 10.1016/j.jphys.2020.03.011.

8. Minghelli B, Soares A, Guerreiro A, Ribeiro A, Cabrita C, Vitoria C, et al. Physiotherapy services in the face of a pandemic. Rev Assoc Med Bras. 2020 Apr; 66(4): 491-7. doi: 10.1590/1806-9282.66. 4.491.

9. Prvu Bettger J, Thoumi A, Marquevich V, De Groote W, Rizzo Battistella L, Imamura M, et al. COVID-19: maintaining essential rehabilitation services across the care continuum. BMJ Glob Health. 2020 May; 5(5): e002670. doi: 10.1136/bmjgh-2020-002670.

10. Verma C, Arora R, Shetye J, Karnik N, Patil P, Mistry H, et al. Guidelines of physiotherapy management in acute care of COVID-19 at dedicated COVID center in Mumbai. Physiother-J Indian Assoc Physiother. 2020; 14(1): 55-60. doi: 10.4103/pjiap.Pjiap_33_20.

11. Abdullahi A. Things to note in stroke rehabilitation. J Nurs Care. 2015; 4(4). doi: 10.4172/21671168.1000266

12. Okezue OC, Nwafor GC, Ezeukwu OA, John JN, Uchenwoke CI. Adherence to home exercise programmes and its associated factors among patients receiving physiotherapy. Clin Health Promot. 2019; 9(1): 7-14.

13. Maunder R, Hunter J, Vincent L, Bennett J, Peladeau N, Leszcz M, et al. The immediate psychological and occupational impact of the 2003 SARS outbreak in a teaching hospital. CMAJ. 2003 May; 168(10): 1245-51.

14. Yang S, Kwak SG, Ko EJ, Chang MC. The mental health burden of the COVID-19 pandemic on physical therapists. Int J Environ Res Public Health. 2020 May; 17(10). doi: 10.3390/ ijerph17103723.

15. Lee AM, Wong JG, McAlonan GM, Cheung V, Cheung C, Sham PC, et al. Stress and psychological distress among SARS survivors 1 year after the outbreak. Can J Psychiatry. 2007 Apr; 52(4): 233-40. doi: 10.1177/070674370705200405.

16. Isah MB, Abdulsalam M, Bello A, Ibrahim MI, Usman A, Nasir A, et al. Coronavirus disease 2019 (COVID-19): knowledge, attitudes, practices (KAP) and misconceptions in the general population of Katsina State. Nigeria: medRxiv; 2020. preprint. doi: 10.1101/2020.06.11.20127936.

17. Obinna C. COVID-19: expert says physical activities, exercise prevents disease conditions. [updated 2020 June 2; cited 2020 September 20]. Available from: https://www.vanguardngr.com/ 2020/06/COVID-19-expert-says-physical-activities-exercise-prevents-disease-conditions/.

18. Abdullahi A, Bello B, Mukhtar NB, Kaka B, Abba MA, Usman JS, et al. Physiotherapy management of COVID-19 in Africa: ongoing efforts, challenges, and future directions. Physiother Theory Pract. 2020 Aug; 36(8): 871-2. doi: 10.1080/09593985.2020.1798163.

19. Abdullahi A. COVID-19 pandemic experience: can it serve as a clarion call to establish or revamp a specialty known as 'Infectious Diseases Physiotherapy'?. Physiotherapy. 2020 Sep; 108: 1. doi: 10.1016/j.physio.2020.05.001. 
20. India, Kanpur University. Syllabus for Bachelor of physiotherapy (BPT) academic program. [cited 2020 September 20]. Available from: www.kanpuruniversity.org/SYLLABUS/BPT.pdf.

21. The Medical Rehabilitation Therapists (Registration) Board of Nigeria [MRTB]. Harmonized curriculum of studies for doctor of physiotherapy (DPT) degree program in Nigerian universities as a standard control measure. [cited 2020 September 20]. Available from: http://www. mrtbnigeria.org/docs/curr/T-DPTCurriculum.pdf.

Corona virus disease 2019 in Nigeria

\section{Corresponding author}

Daha Garba Muhammad can be contacted at: dahagarba@gmail.com

For instructions on how to order reprints of this article, please visit our website:

www.emeraldgrouppublishing.com/licensing/reprints.htm

Or contact us for further details: permissions@emeraldinsight.com 